EPiC Series in Built Environment
Volume 1, 2020, Pages 320-328
Associated Schools of Construction Proceed-
ings of the 56th Annual International Conference

\title{
Design Practitioner's Insights Regarding the Use of Co-Location in Design-Build
}

\author{
Jeffrey Kim, MSc. and Wesley Collins, PhD. and J. Mark Taylor, PhD, JD \\ and Justin Miller, and Jess Donnerberg, MSc. \\ Auburn University \\ Auburn, Alabama
}

Co-location is a process that involves bringing the constituents of a project together in a shared space with the intent of enhancing team effectiveness. When used with the design-build delivery method, formal communication barriers are circumvented. However, do all the project constituents perceive the same value from co-location? This research examines the benefits of co-location when used for a design-build project and includes the perceptions of 101 Design Build Institute of America (DBIA) design practitioners. Within the responses, communication, collaboration, and team chemistry were the most highly ranked benefits with this group. However, the open-ended feedback indicated that project size and complexity, disruptions to intra-organizational collaboration, organizational structure incompatibility for co-location, the absence of the owner and the use of technology were found to be barriers against the use of co-location. Analyzing these perceptions and the barriers shed awareness into a process that may be perceived differently among its constituents - allowing for focus on ways in which to improve co-location.

Key Words: Design-Build, Co-Location, Project Delivery, Designers

\section{Introduction}

Project delivery method selection is one of the most important decisions that an owner makes when seeking to achieve the highest value in return for their construction investment (Abdirad \& Dossick, 2019; Jackson, 2011; Kenig, 2011; Thomsen \& Sanders, 2011). Choosing a project delivery method establishes the tone, pace, and rhythm for the project's participants from project inception through to its completion (Jackson, 2011). There are a variety of delivery methods to choose from, and most projects blend multiple delivery methods to suit the needs of complex and often customized projects (Thomsen \& Sanders, 2011). In many of these delivery methods, much attention goes into how the team will function together for the best interest of the project. One such consideration is co-location (CL). Co-location involves designers and builders (and sometimes others) working side-by-side in a shared location during different periods of a project. It is arguably the most integrative practice that a project team can undertake, providing enhanced collaboration between the design and construction team (Pishdad-Bozorgi, Moghaddam, \& Karasulu, 2013). 
While the prevailing research in both academia and in the commercial sector (Andres, 2002; Barista, 2016; Ocker \& Yaverbaum, 1999; Shuler, 2016) point toward in-face collaboration as the best method for achieving success, there have been few studies that examine, at a deeper level, the perceptions of those directly involved in the practice of CL. CL has been observed to foster accountability, responsiveness, efficiency, and coordination among team members that results in a reduced need to formalize the transfer of information. (Elvin, 2003; Powell \& Champlin, 2009). Therefore, a deeper understanding of the perceptions and concerns of the constituents involved would be warranted in order to improve the process of CL.

\section{Background and Research Rationale}

On the subject of the design-build process, the research literature suggests multiple factors that add overall value. The attention to cost, time, quality, and collaboration are recurrent factors in the designbuild process (Kenig, 2011). Additionally, there is an expectation that focusing on these factors will also improve the design product as well as enhancing the construction process. Furthermore, it is suggested that CL improves the delivery method by facilitating communication and aides in managing project team expectations (Molenaar \& Franz, 2018). In this section, the authors examine these factors in order to support an examination of the design disciplines' perceptions of CL.

\section{Recurrent Factors Identified in Successful Design-Build}

Design-build could be viewed as a return to the master builders of the early fifteenth century, where designer expertise and construction expertise were available from one entity (Jackson, 2011). However, today's built environment is too complex to expect one entity to provide high-quality service for the entire project (Thomsen \& Sanders, 2011). With expertise spread across different groups, owners are challenged to select the most appropriate delivery method while also committing to being a part of the process (Chan, Scott, \& Lam, 2002; Jergeas \& Fahmy, 2006). There is a plethora of research available that focuses on the successful attributes of design-build. For instance, Chan et al. (2002) conducted a meta-analysis of prevailing literature from 1990-2000. Among the many factors identified; cost, time and quality were the highest ranked. While most other research does not dispute these factors, there is also a significant amount of literature that addresses teamwork and collaboration as additionally important factors (Franz, Leicht, Molenaar, \& Messner, 2016; Jackson, 2011; Jergeas \& Fahmy, 2006). Lastly, Franz et al. (2016) conducted a research study that focused on team integration and collaboration and their effects on the efficiency and effectiveness of the design and construction of a project. The academic studies mentioned here all identify common factors that provide a basis for how success can be measured for project delivery.

\section{The Value of Co-Location}

$\mathrm{CL}$ is intended to increase the possibility that a project will be more successful, and when executed properly, the constituents add more value to the project (Gibson, O'Connor, Migliaccio, \& Walewski, 2006). Dossick, Neff, \& Homayouni (2009) found that CL "supports a stronger team orientation to the project through informal communication." (p. 396), speeding communication and hastening decisions. Furthermore, aside from CL's potential benefits to the project, many other industries have realized similar benefits of having constituents working in proximity to one another. In a study conducted by Andres (2002) the researchers evaluated the difference between online meetings and face-to-face meetings of geographically dispersed programmers. Their findings supported the superiority of face- 
to-face meetings and identified significant impact on team productivity, interaction quality, work quality and perceived project success.

\section{The Rationale for Research}

The success factors mentioned above and the importance of $\mathrm{CL}$ as a facet of design-build are essential considerations for an owner when they select a project's delivery method. Yet, are these factors and CL equally valued across all constituents of the built environment? If they are not, the value for the owner may be diminished. Therefore, the authors sought to understand how designers perceived CL and if their perception supported the notion that CL is a determinant for successfully executing design-build projects. It is essential to understand the perceptions of those involved to ensure that CL is administered at the right time and is properly approached by the project constituents.

\section{Methodology}

In this research study, the authors collected data via an online survey from design practitioners of the Design Build Institute of America (DBIA) through a random sampling of its members across the United States. The DBIA distributed the survey via their monthly newsletter for three months at the end of 2018. The survey contained both closed and open-ended questions. This research was guided by determining the perceived effectiveness of CL in the design-build process and analyzing those perceptions against potential barriers to its success. The intent is to achieve an awareness of the design profession's perceptions about CL and how those perceptions shape their current attitudes toward this process.

\section{Results}

The researchers received 405 responses. Those responses were filtered for participants that selfidentified as part of the design discipline. This filtering resulted in 101 responses $(n=101)$. The makeup of design practitioners predominantly self-classified themselves as engineers $(62.4 \%)$, followed by architects $(29.7 \%)$ and then consultants $(7.9 \%) .10 .9 \%$ responded having $0-5$ years of experience and $20.8 \%$ had $6-15$ years of experience. A larger portion of the practitioners had more than 15 years of experience in the industry ( $25.7 \%$ responding $16-25$ years and $42.6 \%$ responding more than 26 years). Lastly, the participants are almost equally divided between operational employees $(50.5 \%)$ and those at a managerial level or higher within their organizations (a combined $49.5 \%$ at or above the managerial level).

The survey included a question asking participants "What do you think the current co-location usage rate is for projects in the US?" Designers perceived that $27.4 \%$ of all design-build projects used CL. Furthermore, they were asked if that rate should be higher, lower or stay the same. Only $7 \%$ thought it should be lower while $66 \%$ felt it should be higher. $15 \%$ suggested that it stay the same and the remaining $12 \%$ were unsure or offered other comments relating to size and complexity of the project.

As previously mentioned, several factors appear in the research literature that can be used to measure the success of CL for a design-build project. These factors were distilled from the literature and the participants were asked to what extent the factors contributed to successful CL. Figure 1 lists the factors along the left side of the graph and the participant responses to a 5-level Likert scale shown as a percentage to the right of each factor. Factors that were more agreeable (higher frequency of 
Strongly Agree responses) appear at the top of the graph and factors that were less agreeable (smaller frequency of Strongly Agree responses) appear at the bottom of the graph.

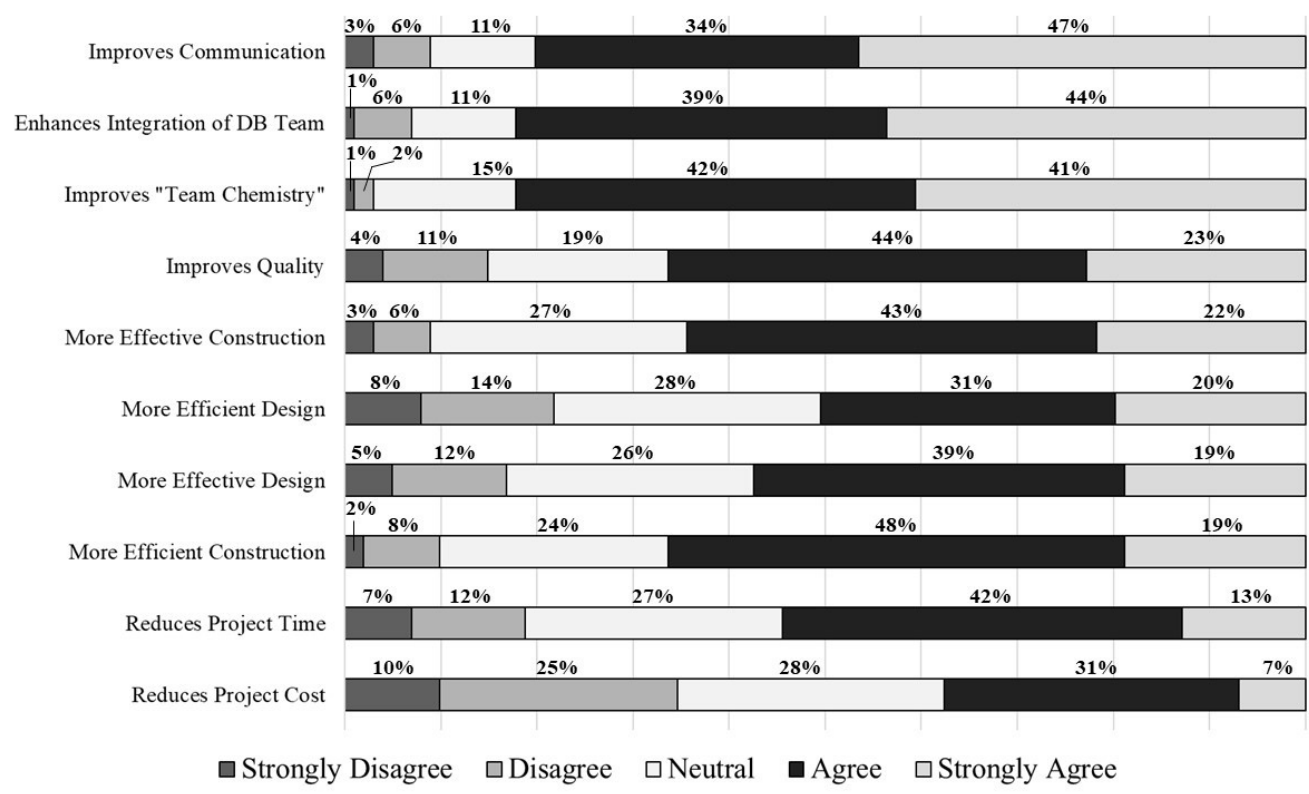

Figure 1. Design Discipline Perceptions of Co-Location Success Factors $(n=101)$

Aside from the demographic data and the success factors analyzed in Figure 1 above, the survey also collected open-ended responses for each question. The participants offered statements that repeatedly appeared throughout their responses. These repeating statements were concerning in that they seemed to hint at disruptions within the CL process. The statements were tallied and categorized as Disruption Themes and their frequency is compared in Table 1.

Table 1

Prevailing Disruption Theme Frequency in Open-Ended Responses (ranked from most frequent to least frequent)

\begin{tabular}{cl}
\hline Frequency & Disruption Theme Description \\
\hline $40 \%$ & Successful design-build is dependent on project size and complexity. \\
$23 \%$ & Co-Location causes a disruption to intra-organizational collaboration. \\
$14 \%$ & Design disciplines are not organizationally structured for co-location. \\
$12 \%$ & The owner must be a part of the co-location effort. \\
$11 \%$ & Technology can help co-location. \\
\hline
\end{tabular}

\section{Discussion}


In this section, the authors examine the design discipline's insights regarding the use of CL on designbuild projects. The participants were requested to provide open-ended feedback to each question within the survey. The intent was to capture qualitative data about each of the success factors listed in Figure 1. The qualitative feedback was examined and categorized into Disruption Themes in Table 1. Lastly, some additional questions in the survey sought feedback on various aspects of the CL process and its use in design-build. Together these responses are examined based on the disruption themes identified in Table 1.

\section{Disruption Theme 1: Successful design-build is dependent on project size and complexity.}

The participants frequently offered that project size and complexity was a dependency in their responses to some of the closed-ended questions. For instance, when asked if co-location was noticed to increase project value, many designers in the open-ended portion of the response noted that it depended upon the project's size and complexity. Furthermore, when the participants were asked about the project size (in monetary terms) that could make the best use of CL, more than $60 \%$ indicated that the project needed to be more than $\$ 150 \mathrm{M}$. Lastly, when asked if CL should be a requirement of the design-build contract, the designers also offered that size and project complexity were dependency factors that should be considered before mandating CL within the contract. Therefore, the consensus seems to indicate that larger projects would be more likely to have the resources necessary to support CL in a design-build project.

Some of the data suggest that the cost of CL is a barrier, and the authors identify it as a sub-theme to project size and complexity. This sub-theme was singled out for analysis by the authors because it was pervasive within nearly all open-ended responses to the survey. Several of the open-ended responses received opinions about the costly setup of CL for the project. Anecdotal feedback suggests that the design discipline does not recognize CL as a credible practice for saving or reducing project cost. These comments are supported by the data in Figure 1 where the success factor, "Reduce project costs", received the least amount of agreeable responses. Furthermore, these responses were qualified by suggesting that the high cost of CL could be absorbed more effectively with larger projects. These data indicate that projects with larger budgets (over $\$ 150 \mathrm{M}$ ) were more likely to obtain economic benefit from the use of CL.

\section{Disruption Theme 2: Co-Location causes a disruption to intra-organizational collaboration.}

Many of the questions concerning co-location received an open-ended response that was not anticipated by the researchers. While the planned benefit of CL is getting the project team to work in harmony, CL seems to have an unfavorable effect on the designer's intra-organizational (within their respective organizations) collaboration. When they are separated from their home office, they become, as one person noted, "isolated on islands apart from their design team". Other supporting responses include the following:

"...frequently more effective to be with your firm's staff rather than the DB team..."

"The excitement dies out and can [be a] morale [sic] issue, as they also want to be a part of the team back at their usual office."

"Co-location is rough on architectural firm culture. It pulls firms apart and employees lose [sic]their sense of firm architectural peer community." 
Lastly, it did not go unnoticed that several participants indicated a separation from the home office also disrupts an employee's chances for promotion and benefit. As one person indicated, "They get 'disconnected', others advance while they are 'stuck on this job'."

From these data it appears that designers seem willing to forego the intra-company issues in the interest of the project. As stated earlier in the paper, the group self-reported that they observe $27.4 \%$ of design-build projects use CL. Most (66\%) favored more CL than what is currently being perceived. This, despite recognizing the negative impact that it has on their intra-organizational relations, may be a reason for modifying the CL process in the future.

\section{Disruption Theme 3: Design disciplines are not organizationally structured for co- location.}

Several professionals shared that their organizational processes and procedures would not be conducive to CL. Separation from their home office separates them from the resources that their home office provides. The design practitioners explained that they work on multiple projects and that working on a single project is not the norm for their design practice. The following responses promote this notion:

"The engineering industry is less mobile than the construction industry."

"...engineers work on several projects at a time and typically have a different production team dedicated to each project."

“...we do not work on only one project at a time."

Aside from the ability to singularly focus key staff on only one project, it was indicated that dedicating the resources of a single design practitioner would be costly unless that project was of a size that could justify a single person for a significant duration of the project. This testimony raises the question that if it is not possible to dedicate one person to a single project, what about dedicating them for a shorter duration, at crucial times throughout the project. Several people suggested that this is how it typically happens and how it will most likely work going forward. Similarly, Abdirad \& Dossick (2019) suggested in their study that in the future, the practice of CL may lead to "restructuring of some dimension of the architectural practice" (p. 104).

\section{Disruption Theme 4: The owner must be a part of the co-location effort.}

While the design practitioners appear hesitatingly agreeable to CL, they often stipulate that for CL to be genuinely successful, the owner must be part of the CL effort. This notion is evident in the following responses:

"Co-location is helped greatly if the owner also co-locates, but few owners do that."

"Co-location also is hurt by Owners who want co-location but do not reciprocate..."

"We need to do a better job in trying to convince [the] owner to co-locate with the design \& construction team." 
The researchers did not specifically address ownership's viewpoint in this research, nor the possible reasons why they were not unanimously a part of the CL effort. Since academically, co-locating the owner is a "critical principle" in the success of design-build projects (Jergeas \& Fahmy, 2006, p. 33), then why is it not unanimously recognized by owners that this practice is for them too? The responses hint toward a consensus that owners must be an active part of the CL and that they are not.

\section{Disruption Theme 5: Technology can help co-location.}

There were many instances where the participants suggested that technology is already an active replacement, in some cases, to CL.

"Networking tools such as video conferencing and cloud storage that serve similar functions to colocation. These are much cheaper and time-effective than co-location..."

"While not a barrier, technologies with communication have helped alleviate the need to colocate (Video conf, webex/zoom mtges, Skype, etc)."

"Not sure co-location is as big a benefit/necessity with technology advances over the last 10-15 years."

While there are some apparent technologies available today that can supplement and possibly replace $\mathrm{CL}$, it was interesting to note that one person suggested that some older technologies were not being appropriately used to their highest effectiveness.

"Phone calls go a long [sic] way in developing a productive working relationship and are generally underutilized."

The scope of this research did not allow for further examination of technology's role in the future of team collaboration and CL. However, with the many responses that were received suggesting technology as the solution, it should be considered a topic for future study.

\section{Conclusion}

It is essential to re-evaluate the benefits of $\mathrm{CL}$ in design-build over time. Because $\mathrm{CL}$ is a highly integrative process (Pishdad-Bozorgi et al., 2013), it is also essential to identify the perceptions of those involved in the process. While this research study concentrated on the design discipline's insights, it would be advantageous to obtain perceptions from the remaining constituents in the process, namely the owner and the construction manager. Contrastingly, a significant issue that warrants further investigation would be why, according to designers, so many owners do not participate in the CL process. Owners too, should recognize that they are an integral and necessary part of the CL process - without them significant decisions go unanswered and become disruptions to the project. The focus for this research was limited to members of the DBIA and likely did not include a significant representation of the design profession. Interpretations of this research should understand that a larger population may have additional or contrary opinions of CL.

Co-location, in its academic sense, is beneficial to the design-build project (Jackson, 2011; Kenig, 2011; Pishdad-Bozorgi et al., 2013); in fact, other industries also recognize this to be true (Andres, 2002). Nevertheless, this notion does not directly translate to how it is perceived in the built environment. As has been discussed, the consistency of its perceived benefit may be at odds among 
the constituents of the project team and economically, larger projects are perceived to obtain these benefits over smaller ones. Moreover, the design disciplines may require "restructuring" (Abdirad \& Dossick, 2019) as they adapt to more collaborative engagements in the built environment. These collaborative engagements may evolve over time to include the use of more technology within the process - many of the participants seemed willing to offer that technology is already being used, in some cases, as a replacement to CL.

From this research study it is apparent that the design discipline values CL for its collaborative benefits and ability to improve team chemistry. Furthermore, they are willing to seeing more CL on design-build projects than what is currently perceived. However, they are not unanimous in their decision to support it for all projects - only those projects of a specific size and complexity. Lastly, they perceive the owner's role in CL to be paramount and attest that many owners do not see it the same way.

\section{References}

Abdirad, H., \& Dossick, C. S. (2019). Restructuration of Architectural Practice in Integrated Project Delivery (IPD): Two Case Studies. Engineering, Construction and Architectural Management, 26(1), 104-117. https://doi.org/10.1108/ECAM-05-2018-0196

Andres, H. P. (2002). A Comparison of Face-to-Face and Virtual Software Development Teams. Team Performance Management: An International Journal, 8, 39-48. https://doi.org/10.1108/13527590210425077

Barista, D. (2016, September). 8 Tips for Perfecting Co-Location. Building Design + Construction. Retrieved from http://www.bdcnetwork.com/8-tips-perfecting-co-location

Chan, A. P. C., Scott, D., \& Lam, E. W. M. (2002). Framework of Success Criteria for Design/Build Projects. Journal of Management in Engineering, 18(3), 120-128. https://doi.org/10.1061/(asce)0742-597x(2002)18:3(120)

Dossick, C. S., Neff, G., \& Homayouni, H. (2009). The Realities of Building Information Modeling for Collaboration in the AEC Industry. Construction Research Congress 2009, 396-405. https://doi.org/10.1061/41020(339)41

Elvin, G. (2003). Proven Practices in Design-Build and Fast-Track. Architectural Engineering Conference (AEI) 2003, 1-8. https://doi.org/10.1061/40699(2003)33

Franz, B., Leicht, R., Molenaar, K. R., \& Messner, J. (2016). Impact of Team Integration and Group Cohesion on Project Delivery Performance. Journal of Construction Engineering and Management, 143(1), 04016088. https://doi.org/10.1061/(asce)co.1943-7862.0001219

Gibson, G. E. J., O’Connor, J. T., Migliaccio, G. C., \& Walewski, J. (2006). Key Implementation Issues and Lessons Learned with Design-Build Projects. Alternative Project Delivery, Procurement, and Contracting Methods for Highways, 1-19. https://doi.org/10.1061/9780784408865

Jackson, B. J. (2011). Design-Build: Design-Build Essentials (Vol. 1). Boston, MA: Delmar Publishing.

Jergeas, G., \& Fahmy, S. (2006). Ten Critical Principles for Successful Design-Build Projects. Cost Engineering, 48(11), 29-34. 
Kenig, M. E. (2011). Project Delivery Systems For Construction (3rd ed.). Washington, D.C.: Associated General Contractors of America.

Molenaar, K. R., \& Franz, B. (2018). Revisiting Project Delivery [1998-2018]. Retrieved from https://dbia.org/wp-content/uploads/2018/11/Cost_Performance_ResearchCII_Pankow2018.pdf

Ocker, R. J., \& Yaverbaum, G. J. (1999). Asynchronous Computer-Mediated Communication versus Face-to-Face Collaboration: Results on Student Learning, Quality and Satisfaction. Group Decision and Negotiation, 8(5), 427-440. https://doi.org/10.1023/A:1008621827601

Pishdad-Bozorgi, P., Moghaddam, E. H., \& Karasulu, Y. (2013). Advancing Target Price and Target Value Design Process in IPD using BIM and Risk-Sharing Approaches. 49th ASC Annual International Conference Proceedings, (Vol. 89, 49). Retrieved from http://ascpro0.ascweb.org/archives/cd/2013/paper/CPRT115002013.pdf

Powell, L. C., \& Champlin, A. (2009). 183A Turnpike: A Design-Build Success Story. Structures 2009, 1431(March 2005), 1-10. https://doi.org/10.1061/41031(341)1

Shuler, T. A. (2016, May). Lessons in Colocation and BIM From Lean Construction. Autodesk.Com. Retrieved from https://www.autodesk.com/redshift/lean-construction/

Thomsen, C., \& Sanders, S. (2011). Program Management 2.0: Concepts and Strategies for Managing Building Programs (revised). The Construction Management Association of America Foundation. 